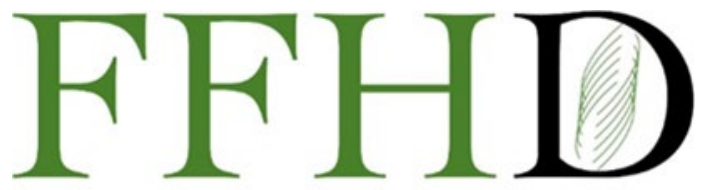

Functional Foods in Health and Disease

\title{
Enhancing effect of glycine and tryptophan mixture on estimated glomerular filtration rate in healthy participants: A randomized, double-blind, placebo-controlled parallel study
}

\author{
Shunji Oshima*, Sachie Shiiya, Yasunori Nakamura
}

Core Technology Laboratories, Asahi Quality and Innovations, Ltd., Ibaraki, Japan

*Corresponding author: Shunji Oshima, PhD, Core Technology Laboratories, Asahi Quality \& Innovations, Ltd., 1-21, Midori 1-chome, Moriya-shi, Ibaraki, 302-0106, Japan.

Submission Date: January $7^{\text {th }}, 2021$; Acceptance Date: January 22 ${ }^{\text {nd }}, 2021$; Publication Date: January $29^{\text {th }}, 2021$

Please cite this article as: Oshima S., Shiiya S., Nakamura Y. Enhancing effect of glycine and tryptophan mixture on estimated glomerular filtration rate in healthy participants: A randomized, double-blind, placebo-controlled parallel study. Functional Foods in Health and Disease 2021. 11(1): 24-33. DOI: https://www.doi.org/10.31989/ffhd.v11i1.774

\footnotetext{
ABSTRACT

Background: The mixture of glycine and tryptophan exhibited serum uric acid-lowering effects in our previous clinical trial.

Objective: Using a randomized, double-blind, placebocontrolled, and parallel study design, this current study aimed to examine whether this mixture enhanced the estimated glomerular filtration rate (eGFR) as an indicator of renal function in healthy individuals.
}

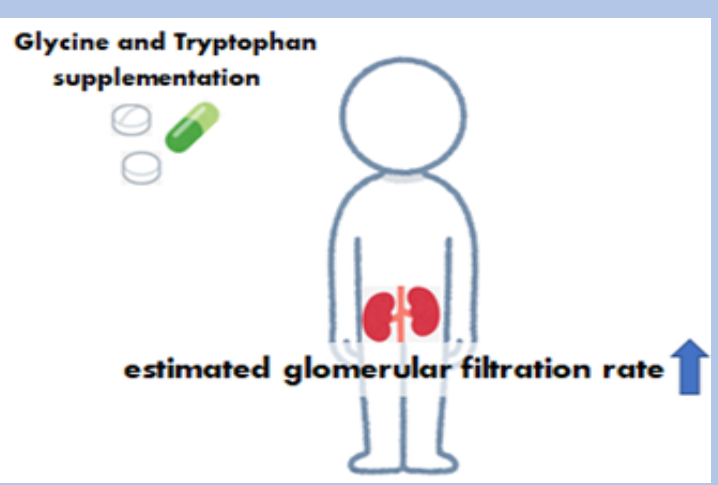

Methods: Healthy Japanese adult males and females ingested a powder mixture containing $3.0 \mathrm{~g}$ of glycine and $0.2 \mathrm{~g}$ of tryptophan or a placebo powder once daily at bedtime for 8 weeks.

Results: After 8 weeks of continual ingestion, the combined glycine and tryptophan supplementation significantly enhanced eGFR. It also decreased serum uric acid levels, consistent with our previous reports. Meanwhile, the continual ingestion of the mixture had no influence on serum total or essential amino acids. 
significantly elevated the eGFR of healthy participants. However, further investigation is required to elucidate the detailed mechanisms underlying the potential therapeutic or preventive effect of combined glycine and tryptophan supplementation. Nevertheless, the uric acid-lowering effect of glycine and tryptophan mixture has the potential to directly influence renal function.

Key words: glycine, tryptophan, estimated glomerular filtration rate, uric acid

CFFC 2021. This is an Open Access article distributed under the terms of the Creative Commons Attribution 4.0 License (http://creativecommons.org/licenses/by/4.0)

\section{BACKGROUND}

Chronic kidney disease (CKD) causes a major burden of morbidity and mortality from noncommunicable diseases, affecting $10 \%$ of the population worldwide [1]. CKD is the leading cause of cardiovascular diseases and premature death as well as end-stage renal disease. Hence, preventing CKD development is essential. The glomerular filtration rate (GFR) is the best overall indicator of renal function. In 1950, Davies and Shock demonstrated that GFR is inversely related to age in males between the ages of 20 and 90 years [2]. Subsequently, GFR has been reported to decline with age in the absence of renal disease $[3,4]$. Since 2000, some studies using longitudinal measures of estimated GFR (eGFR) by either creatinine or cystatin $\mathrm{C}$ have shown that changes in renal function are strongly associated with the risk of developing various CKD-related outcomes [5-9]. The severity of CKD can be quantified by a low serum creatinine or cystatin C-based eGFR; this measure indicates excretory renal function.

The National Kidney Foundation's Kidney Disease Outcomes Quality Initiative has provided evidence-based guidelines for nutrition in kidney diseases since 1999 worldwide. The recent guideline statements focus on the following six primary areas: nutritional assessment, medical nutrition therapy, dietary protein and energy intake, nutritional supplementation, micronutrients, and electrolytes [10]. Our study concentrated on the effects of dietary protein. According to the guideline, protein intake should be avoided among patients with CKD. Protein metabolizes catabolic products such as urea and many degradation products, which are normally cleared by the kidneys; when renal function declines, these products will accumulate in the blood, progressively impairing organ function. Conversely, previous studies observed that protein intake [11-15] and infusion of amino acid mixtures [16-19] had a significant positive effect on the GFR in humans. A Phase II multicenter clinical trial involving 474 critically ill patients investigated the physiological effects of intravenous amino acid therapy on renal function. The therapy did not alter the duration of renal dysfunction, but it increased the eGFR. Hence, amino acid administration can promisingly improve renal function. Unfortunately, it can hardly be applied extensively as one of the preventive strategies for kidney diseases because methods for its intravenous administration are limited. Furthermore, the effects of respective amino acids have not yet been clearly distinguished.

In our two previous clinical trials, the oral administration of the combined dose of glycine and tryptophan led to a decreased concentration of serum uric acid because of the increased urate excretion into the urine $[20,21]$. A recent prospective cohort study suggested that serum uric acid levels are independently associated with the incidence of impaired renal function and renal progression [22], and a meta-analysis reported that uric acid-lowering therapy effectively regards CKD progression [23]. Furthermore, serum uric acid is associated with CKD incidence $[24,25]$. Thus, the present randomized, double-blind, placebo-controlled, clinical study aimed to confirm whether continual combined supplementation with glycine and tryptophan increased the eGFR in healthy participants. 


\section{MATERIALS AND METHODS}

Participants: This clinical study conformed to the Declaration of Helsinki, and the Ethics Committees of Suda Clinic institutional review board approved the study protocol (approval number: 2020-002). Our study participants were all employees of the Asahi Group Research and Development Center (Ibaraki, Japan) and provided written informed consent voluntarily. We included Japanese healthy males and females aged 20-64 years and excluded those with a history of liver, renal, heart, or any severe disease, diabetes, drug or food allergies, routine drug or protein medication, or amino acid supplementation. According to the power analysis performed during the study planning phase, more than 40 participants were needed to be recruited to achieve a study power of 0.8 at a significance level of 0.05 . Thus, we enrolled 40 eligible participants.

Test foods: The test foods (Active or placebo) were the same as those used in a previous clinical trial [20]. Glycine, L-tryptophan, and dextrin were purchased from Yuki Gosei Kogyo Co. Ltd. (Tokyo, Japan), Ajinomoto Healthy Supply, Inc. (Tokyo, Japan), and Matsutani Chemical Industry Co., Ltd. (Tokyo, Japan), respectively. We used dextrin as the placebo. All participants ingested either the Active or placebo food in powder form. Table 1 lists the components of the test foods. Moreover, both the Active and Placebo foods were added with a small amount of lemon flavor (IL78363, Ogawa \& Co. Ltd., Tokyo, Japan) and citric acid (60M, Iwata chemical Co., Ltd., Shizuoka, Japan) to be confused both powders.

Table 1. Components of the test foods

\begin{tabular}{lll}
\hline Components & Active (g) & Placebo (g) \\
\hline Glycine & 3.0 & - \\
L-Tryptophan & 0.2 & - \\
Dextrin & 2.0 & 5.2 \\
Citric acid & 0.18 & 0.18 \\
Lemon flavor & 0.02 & 0.02 \\
\hline
\end{tabular}

Study design: A randomized, placebo-controlled, double-blind parallel design was used for this study, which was registered to UMIN-CTR (University Hospital Medical Information Network, registered ID: UMIN000039742). Figure 1 shows the schedule of the study. Using block randomization, we allocated 42 participants to either Active group or Placebo group. All participants were instructed to maintain daily eating, drinking habit, and a normal level of daily physical activity during the experimental period for 12 weeks (from $0 \mathrm{w}$ to $+4 \mathrm{w}$ ). The Active group ingested a mixture powder of glycine (3.0 g) and tryptophan $(0.2 \mathrm{~g})$ as the Active powder, while the Placebo group ingested the placebo powder, both once daily at bedtime for 8 weeks (from $0 \mathrm{w}$ to $8 \mathrm{w}$ ). We collected peripheral blood samples via the cubital vein and measured their body weight in the morning under overnight fasting condition at the beginning of the trial $(0 \mathrm{w}), 4$ weeks later $(4 \mathrm{w}), 8$ weeks later $(8 \mathrm{w})$, and 12 weeks later, indicating a 4-week span after every ingestion (+4 w).

Measurements: To measure body mass index, we divided the measured body weight by the square of the measured body height. All participants reported their smoking status (current smoker, nonsmoker, or ex-smoker) and drinking habit (every day, 5-6 times/week, 3-4 times/week, 1-2 times/week, <3 times/month, or none). Furthermore, a local laboratory measured serum cystatin $\mathrm{C}$ concentration for clinical examination (LSI Medience Corporation, Tokyo, Japan). eGFR was calculated separately for males and females using serum cystatin $C$ and age according to the equations developed for the 
Japanese population, as previously described [26]. Using a Fuji DRI-CHEM 7000 system (Fujifilm Co., Tokyo, Japan), we measured the serum levels of creatinine, blood urea nitrogen (BUN), total protein, albumin, uric acid, aspartic aminotransferase (AST), alanine aminotransferase (ALT), gamma-glutamyl transferase (GGT), lactate dehydrogenase (LDH), alkaline phosphatase (ALP), creatine kinase (CK), total bilirubin, LDL-cholesterol (LDL-C), HDL-cholesterol (HDL-C), and triglyceride (TG). In addition, serum concentrations of glycine, tryptophan, and other amino acids were analyzed using an analytical method for the automated precolumn derivatization of amino acids; this method was based on HPLC/electrospray ionization mass spectrometry (so-called UF-Amino Station system; Shimadzu, Japan), as previously described [27]. As a sample preparation, a $0.1 \mathrm{~mL}$ portion of the human serum sample was added to 0.1 $\mathrm{mL}$ of the internal standard solution and then $0.2 \mathrm{~mL}$ of acetonitrile was added to the mixed solution for deproteinization. This solution was immediately mixed and then centrifuged, the supernatant solution was used for measurement.

Statistical analyses: All statistical data were analyzed using the BellCurve 2.15 software (SSRI, Tokyo, Japan). Sex, drinking habits, and smoking habits were compared by chi-square test; age and body mass index were compared by Student's t-test. Temporal changes $(0 w, 4 w, 8 w$, and $12 w)$ of each variable were analyzed by Bonferroni's test after a repeatedmeasures analysis of variance. Means with different superscript lowercase letters $(a, b)$ indicate a significant difference $(p<0.05)$. The abovementioned data are expressed as means and standard deviation. Differences in the changes in eGFR and serum uric acid concentration from pre-ingestion to $8 \mathrm{w}$ between the Active and Placebo groups were analyzed by Mann-Whitney $U$ test, and the data are presented as box plots. Differences were considered significant when $p<0.05$.

\section{RESULTS}

Participant characteristics: As shown in Figure 1, 42 participants were enrolled according to the abovementioned criteria. However, two of them withdrew their consent at their own convenience during the study, and one was excluded from the analyses because of failure to comply with the protocol (low compliance in test food ingestion, and food consumption before blood collection). Ultimately, we analyzed 39 participants aged 25-53 years (Active: $34.4 \pm 7.1$, Placebo: $36.3 \pm 8.6$ ) (Table 2). The rates of ingestion compliance were $99.5 \%$ in Active and $99.2 \%$ in Placebo. Age, sex, body mass index, drinking habit, and smoking habit were not different between the two groups.

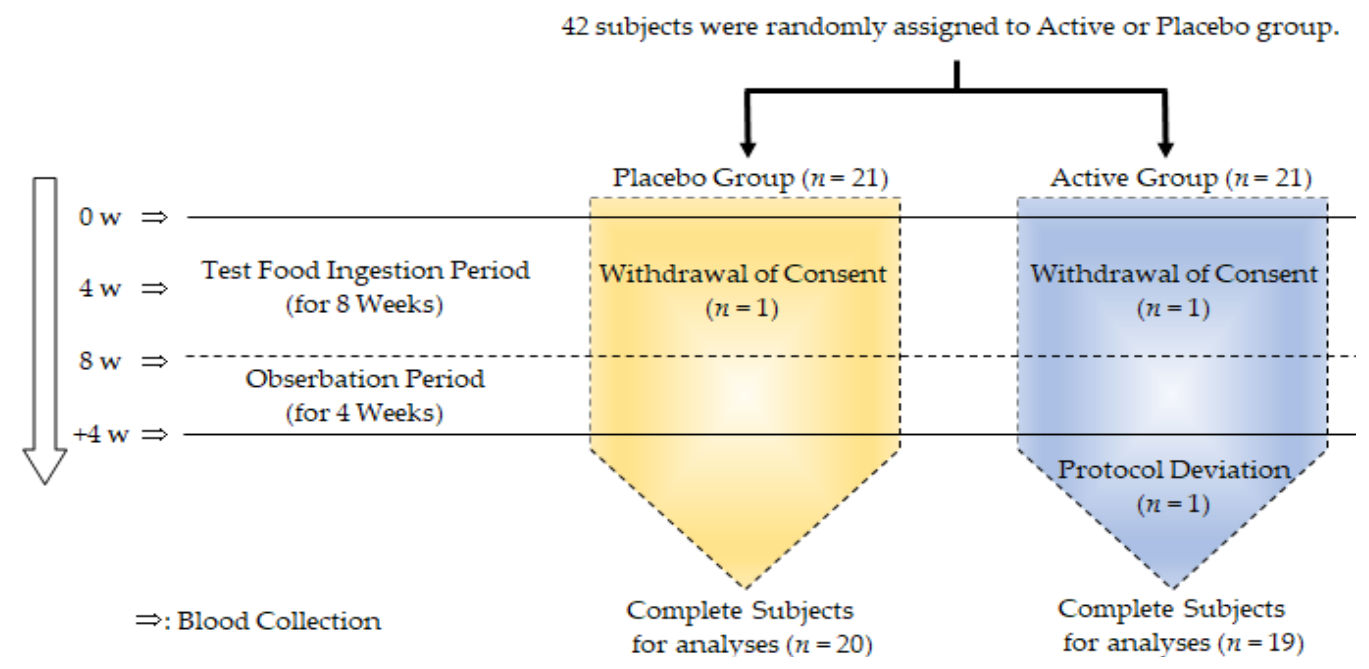

Figure 1. Experimental schedule showing the randomized, double-blind, placebo-controlled, parallel study design. The study was performed over a 12-week period. 
Table 2. Characteristics of the healthy participants $(n=39)$.

\begin{tabular}{llll}
\hline Parameters & Active $(\boldsymbol{n}=\mathbf{1 9})$ & Placebo $(\boldsymbol{n}=\mathbf{2 0})$ & $\boldsymbol{p}$ Value \\
\hline Age $($ years $)$ & $34.4(7.1)$ & $36.3(8.6)$ & $0.474^{\mathrm{a}}$ \\
Male $(n)$ & 8 & 11 & $0.421^{\mathrm{b}}$ \\
Females $(n)$ & 11 & 9 & $0.979^{\mathrm{a}}$ \\
Body mass index $\left(\mathrm{kg} / \mathrm{m}^{2}\right)$ & $22.6(2.7)$ & $22.7(4.0)$ & \\
Drinking habits & & & \\
Every day & 2 & 2 & \\
5-6 Times/week & 2 & 2 & $0.992^{\mathrm{b}}$ \\
3-4 Times/week & 3 & 4 & \\
1-2 Times/week & 10 & 9 & \\
$<3$ Times/month & 1 & 2 & \\
None & 1 & 1 & $0.119^{\mathrm{b}}$ \\
Smoking habits & & & \\
Smoker & 0 & 4 & \\
Nonsmoker & 18 & 15 & \\
Ex-smoker & 1 & 1 & \\
Data are presented as means (standard deviations); ${ }^{\text {a Student's t-test and }}{ }^{\mathrm{b}}$ chi-square test between the Active and Placebo groups.
\end{tabular}

Table 3. Changes of eGFR $\left(\mathrm{ml} / \mathrm{min} / 1.73 \mathrm{~m}^{2}\right)$ during the clinical study.

\begin{tabular}{lllll}
\hline Parameters & Before ingestion & 4 Weeks later & $\mathbf{8}$ Weeks later & $\begin{array}{l}\text { 4 Weeks later after finishing } \\
\text { ingestion }\end{array}$ \\
\hline Active, $n=19$ & $0 \mathrm{w}$ & $4 \mathrm{w}$ & $8 \mathrm{w}$ & $+4 \mathrm{w}$ \\
\hline Placebo, $n=20$ & $119(16)^{\mathrm{a}}$ & $120(14)^{\mathrm{a}}$ & $131(16)^{\mathrm{b}}$ & $132(16)^{\mathrm{b}}$ \\
\hline
\end{tabular}

Data are presented as means (standard deviations); Means with different superscript lower-case letters $\left({ }^{a},{ }^{b}\right)$ are significantly different at $p<0.05$ by Bonferroni's test after a repeated-measures analysis of variance in each group. Abbreviation: eGFR (estimated glomerular filtration rate).

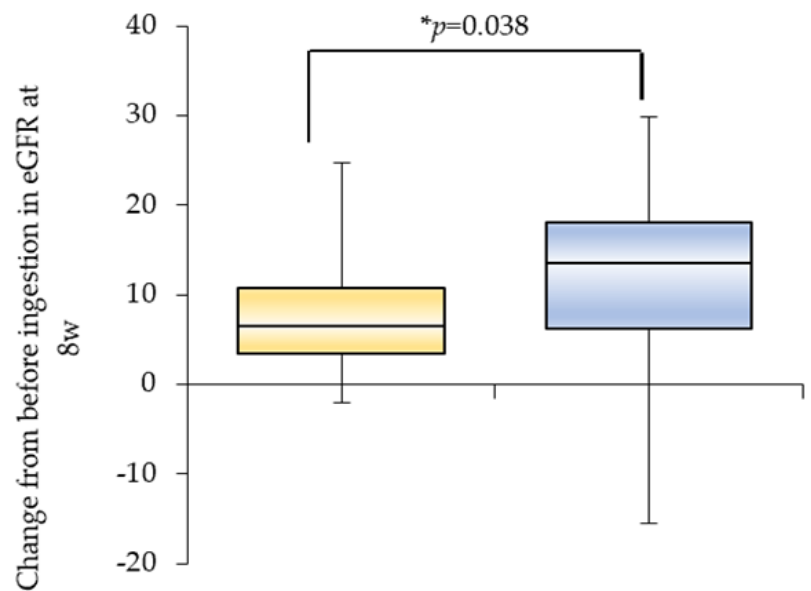

\section{Placebo Active}

Figure 2. Change amounts of eGFR from pre-ingestion $(0 \mathrm{w})$ to 8 weeks later $(8 \mathrm{w})$. These non-parametric data are expressed as box plots; * Mann-Whitney $U$ test between the Active and Placebo groups. Abbreviation: eGFR (estimated glomerular filtration rate).

eGFR: At $0 \mathrm{w}$, the eGFR values of the participants $(n=$ 39) were between 154 and 86. Table 3 and Figure 2 summarize the eGFR values calculated from the serum cystatin $\mathrm{C}$ concentrations of the Active or Placebo group as the main outcome during the trial. At $8 w$ and $12 w(+4 w)$, the eGFR values of both the 
Active and Placebo groups were significantly higher than those at $0 \mathrm{w}$ and $4 \mathrm{w}$. However, the change amount before ingestion at $8 \mathrm{w}$ of the Active group was significantly higher than that of the Placebo group ( $p=0.038$ ) (median: 13 vs. 7; quantiles: 12 vs. 7) (Figure 2).

Other parameters: In addition to the eGFR as the main outcome, influences of the continual ingestion of glycine and tryptophan mixture for 8 weeks were evaluated by plural analyses (Table 4). Serum uric acid and albumin concentrations significantly changed during the study; moreover, the change amount of uric acid at $8 \mathrm{w}$ from $0 \mathrm{w}$ in the Active group was significantly lower than that in the Placebo group (Figure 3). Other serum parameters in the Active group did not temporally change. In contrast, the body mass index, and the serum levels of albumin, LDH, ALP, total bilirubin, and HDL-C in the Placebo group significantly changed. The LDH and total bilirubin levels at $8 \mathrm{w}$ were lower than those at $0 \mathrm{w}$ during the ingestion period of placebo foods.

Table 4. Changes in body mass index and clinical serum parameters in the Active and Placebo groups.

\begin{tabular}{|c|c|c|c|c|c|c|}
\hline Parameters & Units & Groups & Before ingestion & 4 Weeks later & 8 Weeks later & $\begin{array}{l}4 \text { Weeks later after } \\
\text { finishing ingestion }\end{array}$ \\
\hline & & & $0 w$ & $4 w$ & $8 w$ & $+4 w$ \\
\hline \multirow[t]{2}{*}{ Body mass index } & $\mathrm{kg} / \mathrm{m}^{2}$ & Active, $n=19$ & $22.7(2.7)$ & $22.6(2.7)$ & $22.7(2.8)$ & $22.5(2.7)$ \\
\hline & & Placebo, $n=20$ & $22.7(4.0)^{a}$ & $22.6(4.0)^{a b}$ & $22.6(4.0)^{a b}$ & $22.6(4.1)^{b}$ \\
\hline \multirow[t]{2}{*}{ Creatinine } & $\mathrm{mg} / \mathrm{dL}$ & Active, $n=19$ & $0.72(0.15)$ & $0.72(0.14)$ & $0.72(0.17)$ & $0.73(0.18)$ \\
\hline & & Placebo, $n=20$ & $0.74(0.17)$ & $0.74(0.15)$ & $0.76(0.15)$ & $0.74(0.14)$ \\
\hline \multirow[t]{2}{*}{ BUN } & $\mathrm{mg} / \mathrm{dL}$ & Active, $n=19$ & $13.0(2.5)$ & $13.4(2.3)$ & $13.2(1.8)$ & $12.8(2.0)$ \\
\hline & & Placebo, $n=20$ & $13.1(4.2)$ & $12.8(3.8)$ & $12.6(4.6)$ & $12.1(3.3)$ \\
\hline \multirow[t]{2}{*}{ Total protein } & $\mathrm{g} / \mathrm{dL}$ & Active, $n=19$ & $7.4(0.3)$ & $7.2(0.7)$ & $7.3(0.4)$ & $7.2(0.3)$ \\
\hline & & Placebo, $n=20$ & $7.4(0.3)$ & $7.4(0.3)$ & $7.4(0.4)$ & $7.3(0.3)$ \\
\hline \multirow[t]{2}{*}{ Albumin } & $\mathrm{g} / \mathrm{dL}$ & Active, $n=19$ & $5.0(0.4)^{a}$ & $5.0(0.4)^{a}$ & $5.0(0.3)^{a}$ & $4.8(0.3)^{b}$ \\
\hline & & Placebo, $n=20$ & $5.0(0.2)^{a b}$ & $5.1(0.3)^{a}$ & $4.9(0.3)^{a b}$ & $4.9(0.2)^{b}$ \\
\hline \multirow[t]{2}{*}{ Uric acid } & $\mathrm{mg} / \mathrm{dL}$ & Active, $n=19$ & $6.0(2.1)^{a}$ & $5.4(1.6)^{a b}$ & $5.3(1.6)^{b}$ & $5.5(1.3)^{a b}$ \\
\hline & & Placebo, $n=20$ & $5.7(1.5)$ & $5.6(1.2)$ & $5.7(1.3)$ & $5.5(1.5)$ \\
\hline \multirow[t]{2}{*}{ AST } & UI & Active, $n=19$ & $21(4)$ & $19(3)$ & $19(5)$ & $19(4)$ \\
\hline & & Placebo, $n=20$ & $20(3)$ & $20(4)$ & $20(4)$ & $20(3)$ \\
\hline \multirow[t]{2}{*}{ ALT } & UI & Active, $n=19$ & $17(8)$ & $16(7)$ & $16(8)$ & $16(8)$ \\
\hline & & Placebo, $n=20$ & $16(7)$ & $18(7)$ & $18(8)$ & $17(7)$ \\
\hline \multirow[t]{2}{*}{ GGT } & UI & Active, $n=19$ & $20(9)$ & $21(13)$ & $22(9)$ & $21(9)$ \\
\hline & & Placebo, $n=20$ & $24(30)$ & $24(22)$ & $27(27)$ & $27(28)$ \\
\hline \multirow[t]{2}{*}{$\mathrm{LDH}$} & UI & Active, $n=19$ & $152(18)$ & $147(15)$ & $146(28)$ & $142(17)$ \\
\hline & & Placebo, $n=20$ & $161(28)^{a}$ & $158(31)^{a b}$ & $154(26)^{b}$ & $157(27)^{a b}$ \\
\hline \multirow[t]{2}{*}{ ALP } & UI & Active, $n=19$ & 169 (39) & $171(40)$ & $173(39)$ & $176(45)$ \\
\hline & & Placebo, $n=20$ & $171(39)^{a}$ & $171(35)^{a}$ & $175(36)^{a b}$ & $182(41)^{b}$ \\
\hline \multirow[t]{2}{*}{ CK } & $\mathrm{UI}$ & Active, $n=19$ & $122(58)$ & $118(60)$ & $97(38)$ & $101(42)$ \\
\hline & & Placebo, $n=20$ & $114(43)$ & $124(65)$ & $108(44)$ & $113(41)$ \\
\hline \multirow[t]{2}{*}{ Total bilirubin } & $\mathrm{mg} / \mathrm{dL}$ & Active, $n=19$ & $0.8(0.3)$ & $0.7(0.4)$ & $0.6(0.3)$ & $0.6(0.2)$ \\
\hline & & Placebo, $n=20$ & $0.7(0.3)^{a}$ & $0.6(0.3)^{a b}$ & $0.5(0.2)^{b}$ & $0.5(0.2)^{b}$ \\
\hline LDL-C & $\mathrm{mg} / \mathrm{dL}$ & Active, $n=19$ & $109(32)$ & $109(37)$ & $111(34)$ & $104(33)$ \\
\hline \multirow[t]{2}{*}{ HDL-C } & $\mathrm{mg} / \mathrm{dL}$ & Active, $n=19$ & $66(18)$ & 65 (17) & $69(16)$ & $67(16)$ \\
\hline & & Placebo, $n=20$ & $65(13)^{a b}$ & $64(12)^{a}$ & $66(14)^{a b}$ & $68(14)^{b}$ \\
\hline \multirow[t]{2}{*}{ Triglyceride } & $\mathrm{mg} / \mathrm{dL}$ & Active, $n=19$ & $81(43)$ & $91(69)$ & $89(44)$ & $93(43)$ \\
\hline & & Placebo, $n=20$ & $81(37)$ & $81(37)$ & $88(46)$ & $81(56)$ \\
\hline
\end{tabular}

Data are presented as means (standard deviations); Means with different superscript lowercase letters $\left({ }^{a},{ }^{b}\right)$ are significantly different at $p<0.05$ by Bonferroni's test following a repeated-measures analysis of variance in each group. Abbreviation: blood urea nitrogen (BUN), aspartic aminotransferase (AST), alanine aminotransferase (ALT), gamma-glutamyl transferase (GGT), lactate dehydrogenase (LDH), alkaline phosphatase (ALP), creatine kinase (CK), LDL-cholesterol (LDL-C), and HDL-cholesterol (HDL-C). 


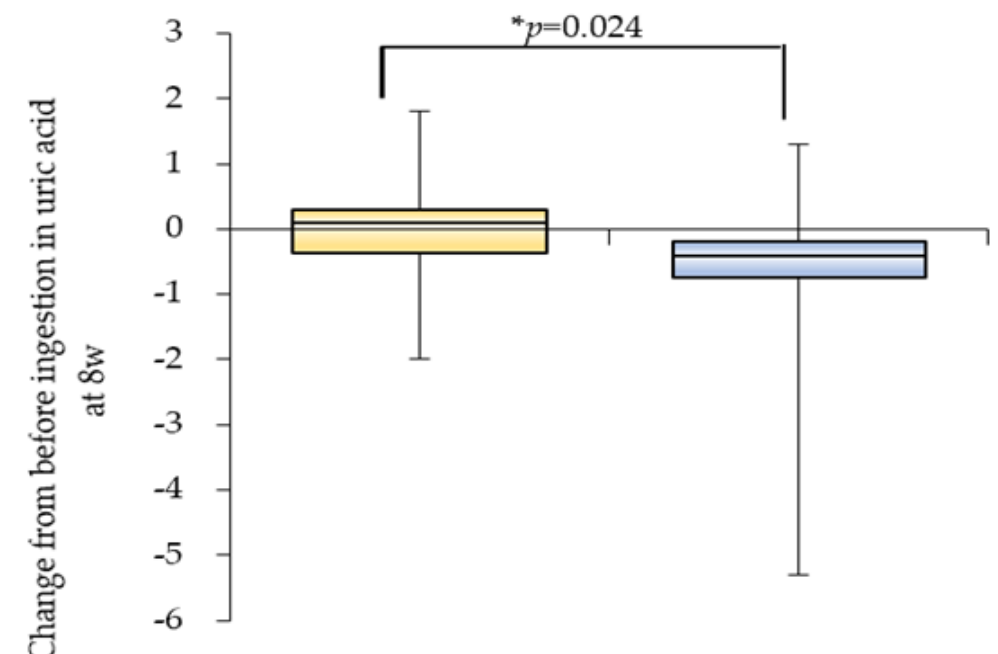

Placebo Active

Figure 3. Change amounts of serum uric acid concentrations from pre-ingestion $(0 \mathrm{w})$ to 8 weeks later ( 8 w). These nonparametric data are expressed as box plots; * Mann-Whitney $\mathrm{U}$ test between the Active and Placebo groups.

\section{Amino acids in serum levels}

Table 5 lists the concentrations of serum amino acids during the study period. Serum glycine concentrations in the Active group significantly increased, but that in the Placebo group did not change. During the trial, both groups maintained the levels of serum tryptophan, essential amino acids (histidine, isoleucine, leucine, lysine, methionine, phenyl-alanine, threonine, tryptophan, and valine), and total amino acids (alanine, arginine, asparagine, aspartic acid, citrulline, cystine, glutamic acid, glutamine, glycine, serine, histidine, isoleucine, leucine, lysine, methionine, ornithine, phenylalanine, proline, taurine, theanine, threonine, tryptophan, tyrosine, and valine).

Table 5. Changes in serum amino acid concentrations in the Active and Placebo groups.

\begin{tabular}{|c|c|c|c|c|c|c|}
\hline Amino acids & Units & Groups & $\begin{array}{l}\text { Before } \\
\text { ingestion }\end{array}$ & 4 Weeks later & 8 Weeks later & $\begin{array}{l}4 \text { Weeks later } \\
\text { after finishing } \\
\text { ingestion }\end{array}$ \\
\hline \multirow[t]{2}{*}{ Glycine } & $\mathrm{nmol} / \mathrm{mL}$ & Active, $n=19$ & $161(42)^{a}$ & $198(54)^{b}$ & $189(57)^{b}$ & $158(35)^{a}$ \\
\hline & & Placebo, $n=20$ & $164(32)^{a b}$ & $172(31)^{a}$ & $164(22)^{a b}$ & $151(29)^{b}$ \\
\hline \multirow[t]{2}{*}{ L-Tryptophan } & $\mathrm{nmol} / \mathrm{mL}$ & Active, $n=19$ & $61(12)$ & $59(12)$ & $59(11)$ & $58(11)$ \\
\hline & & Placebo, $n=20$ & $60(11)$ & $62(12)$ & $59(12)$ & $60(11)$ \\
\hline \multirow[t]{2}{*}{ Essential AA } & $\mathrm{nmol} / \mathrm{mL}$ & Active, $n=19$ & 733 (96) & 700 (68) & $713(88)$ & 738 (99) \\
\hline & & Placebo, $n=20$ & 731 (99) & 723 (77) & 702 (90) & 714 (103) \\
\hline \multirow[t]{2}{*}{ Total AA } & $\mathrm{nmol} / \mathrm{mL}$ & Active, $n=19$ & $4,382(671)$ & $4,337(601)$ & 4,277 (605) & $4,306(510)$ \\
\hline & & Placebo, $n=20$ & $4,465(568)$ & $4,421(577)$ & 4,307 (426) & $4,351(600)$ \\
\hline
\end{tabular}

Means with different superscript lowercase letters $(\mathrm{a}, \mathrm{b})$ are significantly different at $p<0.05$ by Bonferroni's test following a repeated-measures analysis of variance in each group. Essential AA includes 9 kinds of amino acid concentrations, and total AA includes 24 kinds of amino acid concentrations. Abbreviation: amino acids (AA). 


\section{DISCUSSION}

Protein or a mixture of amino acids (AA) improves renal function [16-19], but the effects of respective AA are not yet clearly distinguished. In our two previous trials, the combined dose of glycine and tryptophan was orally administered; consequently, the excretion of urates into the urine was enhanced, leading to the decreased concentration of serum uric acid $[20,21]$. The AA may have an effect on renal function. In fact, a single combination dosage of glycine and tryptophan transiently increased eGFR, which as an indicator of renal function, in a preliminary human study (unpublished data). Thus, this study aimed to confirm whether eGFR could be enhanced by continual supplementation with combined glycine and tryptophan in healthy participants. The dosage of $A A$ was based on a previous supplementation study [20]. Glycine metabolizes various end-products, such as glutathione, nucleic acid bases, heme, creatine, and bile [28]. Metabolization from glycine to creatinine through creatine might influence the serum creatinine level. Lees et al. reported that eGFR calculated by cystatin $\mathrm{C}$ was the most strongly associated with cardiovascular disease and mortality, and traditional eGFR from creatinine-based measures were weakly associated with the risk [29]. Cystatin C is freely filtered at the glomerulus, and it is not influenced by body habitus, muscle mass, weight, nor age [30]. Cystatin $C$ has been globally available for over 10 years. It is a more sensitive measure to estimate renal function. Thus, we used serum cystatin $\mathrm{C}$ but not creatinine for calculating the eGFR.

Razak et al. reviewed some overwhelming reports supporting the role of supplementary glycine in prevention of many diseases and disorders excluding kidney lesion [31]. The current study demonstrated that the combined oral administration of glycine and tryptophan significantly elevated the eGFR of healthy participants. This mixture also decreased the serum uric acid levels, consistent with our previous reports [20,21]. No differences were observed in the effect of glycine and tryptophan supplementation between males and females, although the previous studies included mostly male participants. Moreover, elevation in urinary $\mathrm{pH}$ caused by glycine and tryptophan supplementation enhanced the solubility of urinary uric acid, thereby increasing urinary uric acid excretion and urate clearance [21]. Uedono et al. examined the relationship between serum uric acid levels and renal hemodynamic parameters in healthy participants [32]. The serum uric acid levels had a significant inverse U-shaped relationship with GFR or renal plasma flow. The potential mechanisms underlying renal damage caused by uric acid accumulation may be afferent arteriopathy, inflammation, and activation of the renin-angiotensin system [33]. The effects of elevated uric acid are thought to be caused by a direct toxic effect of uric acid on the kidney. The uric acidlowering effect by glycine and tryptophan mixture has the potential to directly influence renal function. Moreover, the infusion of $A A$ in-creased the renal plasma flow measured as para-aminohippurate clearance $[17,18]$. The improved eGFR by glycine and tryptophan may be related to the increase in renal plasma flow. Further studies are required to clarify the mechanism underlying the enhancing effects of glycine and tryptophan on eGFR.

The safety of the amino acid, glycine, or tryptophan has been already established because the AA from various proteins or some dietary supplements are generally part of our daily diet. In clinical trials, up to $90 \mathrm{~g}$ of glycine or $5.0 \mathrm{~g}$ of Ltryptophan a day was consumed without serious adverse effects [34,35]. Furthermore, our previous human study confirmed that the two AA are safe, considering that they were continually ingested for 6 weeks [20]. In the current clinical trial, supplementation of combined glycine, and tryptophan did not result in any adverse events. The physiological parameters did not also change from normal to abnormal values in each participant, as well as the serum concentrations of L-tryptophan, total $A A$, and essential AA. Meanwhile, the supplementation of glycine and tryptophan increased the serum glycine level within the normal range. Thus, supplementation with combined $3.0 \mathrm{~g}$ of glycine and 
$0.2 \mathrm{~g}$ of tryptophan a day was proven safe.

One of the limitations in the current clinical study is the duration of intervention, which was merely 8 weeks as the parallel study design. More long-term trials might achieve considerably more beneficial effects on the outcomes. The eGFR values of the healthy participants were within the normal range; however, the effectiveness of the amino acid mixture to patients with renal diseases remains unknown. At least, daily supplementation of the mixture could be expected to play a preventive role against the decline in renal function of people with no renal diseases. Further studies are warranted to ensure the therapeutic effects and interaction with other effective materials of combined glycine and tryptophan supplementation.

\section{CONCLUSIONS}

The current randomized, double-blind, placebocontrolled, parallel clinical study revealed that daily supplementation with combined $3.0 \mathrm{~g}$ of glycine and $0.2 \mathrm{~g}$ of tryptophan for 8 weeks significantly elevated the eGFR as an indicator of renal function in 39 healthy participants. In addition, this combined amino acid treatment significantly decreased serum uric acid concentrations, consistent with the previous study. In future studies, the mechanisms underlying the potential therapeutic or preventive effect of combined glycine and tryptophan supplementation should be elucidated to thoroughly describe the

\section{REFERENCES}

1. Jha V, Garcia-Garcia G, Iseki K, Li Z, Naicker S, Plattne B: Chronic kidney disease: global dimension and perspectives. Lancet, 2013, 382: 260-272.

2. Davies DF, Shock NW: Age changes in glomerular filtration rate, effective renal plasma flow, and tubular excretory capacity in adult males. Journal of Clinical Investigation, 1950, 29: 496-507.

3. Kaysen GA, Myers BD: The aging kidney. Clinics in Geriatric Medicine, 1985, 1: 207-222.

4. Anderson S, Brenner BM: Effects of aging on the renal glomerulus. The American Journal of Medicine, 1986, 80: 435-442.

5. Rifkin DE, Shlipak MG, Katz R, Fried LF, Siscovick D, Chonchol M, Newman AB, Sarnak MJ: Rapid kidney function decline and mortality risk in older adults. preventive or therapeutic usefulness of this amino acid mixture.

List of Abbreviations: eGFR: estimated glomerular filtration rate, CKD: Chronic kidney disease, BUN: blood urea nitrogen, AST: aspartic aminotransferase, ALT: alanine aminotransferase, GGT: gamma-glutamyl transferase, LDH: lactate dehydrogenase, ALP: alkaline phosphatase, CK: creatine kinase, LDL-C: LDLcholesterol, HDL-C: HDL-cholesterol, TG: triglyceride, HPLC: high performance liquid chromatography, AA: amino acids.

Conflicts of Interest: All authors are employed by Asahi Quality \& Innovations, Ltd.

Author's Contributions: Study design, statistical analysis, result interpretation, and manuscript writing, S.O.; contributed to serum amino acids analysis, S.S.; supervision, Y.N.; final manuscript approval, S.O., S.S., and Y.N..

Acknowledgements and Funding: We would like to thank Y. Ito (Asahi Quality \& Innovations, Ltd.) for help conducting on the study, and IMEQRD Co., Ltd. (Tokyo, Japan) for conducting to approve the protocol by the Ethics Committees of Suda Clinic institutional review board. We also thank Enago (www.enago.jp) for the English language review. This research was funded by Asahi Quality \& Innovations, Ltd.
Archives of Internal Medicine, 2008, 168: 2212-2218.

6. Shlipak MG, Katz R, Kestenbaum B, Siscovick D, Fried L, Newman A, Rifkin D, Sarnak MJ: Rapid decline of kidney function increases cardiovascular risk in the elderly. Journal of the American Society of Nephrology, 2009, 20: 2625-2630.

7. Turin TC, Coresh J, Tonelli M, Stevens PE, de Jong PE, Farmer CK, Matsushita K, Hemmelgarn BR: Short-term change in kidney function and risk of end-stage renal disease. Nephrology Dialysis Transplantation, 2012, 27: 3835-3843.

8. Turin TC, Coresh J, Tonelli M, Stevens PE, de Jong PE, Farmer CK, Matsushita K, Hemmelgarn BR: One-year change in kidney function is associated with an increased mortality risk. American Journal of Nephrology, 2012, 36: 
41-49.

9. Turin TC, Coresh J, Tonelli M, Stevens PE, de Jong PE, Farmer CK, Matsushita K, Hemmelgarn BR: Change in the estimated glomerular filtration rate over time and risk of all-cause mortality. Kidney International, 2013, 83: 684691.

10. Ikizler TA, Burrowes JD, Byham-Gray LD, Campbell KL, Carrero JJ, Chan W, Fouque D, Friedman AN, Ghaddar S, Goldstein-Fuchs DJ, Kaysen GA, Kopple JD, Teta D, Wang AY-M, Cuppari L: KDOQI clinical practice guideline for nutrition in CKD: 2020 update. American Journal of Kidney Diseases, 2020, 76: S1-S107.

11. Addis T, Barrett E, Poo LJ, Ureen HJ, Lippman RW. The relation between protein consumption and diurnal variations of the endogenous creatinine clearance in normal individuals. Journal of Clinical Investigation, 1951, 30: 206-209.

12. Pullman TN, Alving AS, Dern RJ, Landowne M: The influence of dietary protein intake on specific renal function in normal man. Journal of Laboratory and Clinical Medicine, 1954, 44: 320-332.

13. Bosch JP, Saccaggi A, Lauer A, Ronco C, Belledonne M, Glabman S: Renal functional reserve in humans: effect of protein intake on glomerular filtration rate. The American Journal of Medicine, 1983, 75: 943-950.

14. Hostetter TH: Human renal response to meat meal. American Journal of Physiology-Renal Physiology, 1986, 250: F613-F618.

15. Viberti G, Bognetti E, Wiseman MJ, Dodds R, Gross JL, Keen $\mathrm{H}$ : Effect of protein-restricted diet on renal response to a meat meal in humans. American Journal of PhysiologyRenal Physiology, 1987, 253: F388-F393.

16. Graf H, Stummvoll HK, Luger A, Prager R: Effect of amino acid infusion on glomerular filtration rate. The New England Journal of Medicine, 1983, 308: 159-160.

17. Ter Wee PM, Rosman JB, Van Der Geest S, Sluiter WJ, Donker AJ: Renal hemodynamics during separate and combined infusion of amino acids and dopamine. Kidney International, 1986, 29: 870-874.

18. Fliser D, Zeier M, Nowack R, Ritz E: Renal functional reserve in healthy elderly subjects. Journal of the American Society of Nephrology, 1993, 3: 1371-1377.

19. Doig GS, Simpson F, Bellomo R, Heighes PT, Sweetman EA, Chesher D, Pollock C, Davies A, Botha J, Harrigan P, Reade $M C$ : Intravenous amino acid therapy for kidney function in critically ill patients: a randomized controlled trial. Intensive Care Medicine, 2015, 41: 1197-1208.

20. Oshima S, Shiiya S, Nakamura Y: Serum uric acid-lowering effects of combined glycine and tryptophan treatments in subjects with mild hyperuricemia: A randomized, doubleblind, placebo-controlled, crossover study. Nutrients, 2019, 11: 564.

21. Oshima S, Shiiya S, Nakamura Y: Combined supplementation with glycine and tryptophan reduces purine-induced serum uric acid elevation by accelerating urinary uric acid excretion: A randomized, single-blind, placebo-controlled, crossover study. Nutrients, 2019, 11: 2562.

22. Aiumtrakul N, Wiputhanuphongs P, Supasyndh O, Satirapoj B: Hyperuricemia and impaired renal function: A prospective cohort study. Kidney Diseases, 2020: 1-9.

23. Liu X, Zhai T, Ma R, Luo C, Wang H, Liu L: Effects of uric acidlowering therapy on the progression of chronic kidney disease: a systematic review and meta-analysis. Renal Failure, 2018, 40: 289-297.

24. Li L, Yang C, Zhao Y, Zeng $X$, Liu F, Fu P: Is hyperuricemia an independent risk factor for new onset chronic kidney disease? A systematic review and meta-analysis based on observational cohort studies. BMC Nephrology, 2014, 15: 122.

25. Zhu P, Liu Y, Han L, Xu G, Ran JM: Serum uric acid is associated with incident chronic kidney disease in middle-aged populations: a meta-analysis of 15 cohort studies. PLOS ONE, 2014, 9: e100801.

26. Horio M, Imai E, Yasuda Y, Watanabe T, Matsuo S: GFR estimation using standardized serum cystatin $C$ in Japan. American Journal of Kidney Diseases, 2013, 61: 197-203.

27. Yoshida $\mathrm{H}$, Kondo K, Yamamoto $\mathrm{H}$, Kageyama N, Ozawa $\mathrm{S}$, Shimbo K, Muramatsu T, Imaizumi A, Mizukoshi T, Masuda J, Nakayama D, Hayakawa Y, Watanabe K, Mukaibatake K, Miyano $\mathrm{H}$ : Validation of an analytical method for human plasma free amino acids by high-performance liquid chromatography ionization mass spectrometry using automated precolumn derivatization. Journal of Chromatography B, 2015, 998: 88-96.

28. Reeds PJ, Mersmann HJ. Protein and energy requirements of animals treated with $\beta$-adrenergic agonists: $A$ discussion. Journal of Animal Science, 1991, 69: 15321550.

29. Lees JS, Welsh CE, Celis-Morales CA, Mackay D, Lewsey J, Gray SR, Lyall DM, Cleland JD, Gill JMR, Jhund PS, Pell J, Sattar N, Welsh P, Mark PB: Glomerular filtration rate by differing measures, albuminuria and prediction of cardiovascular disease, mortality and end-stage kidney disease. Nature Medicine, 2019, 25: 1753-1760.

30. Ferguson TW, Komenda P, Tangri N: Cystatin $\mathrm{C}$ as a biomarker for estimating glomerular filtration rate. Current Opinion in Nephrology and Hypertension, 2015, 24: 295-300.

31. Razak MA, Begum PS, Viswanath B, Rajagopal S: Multifarious beneficial effect of nonessential amino acid, glycine: a review. Oxidative medicine and cellular longevity, 2017, 2017.

32. Uedono $H$, Tsuda A, Ishimura E, Nakatani S, Kurajoh M, Mori K, Uchida J, Emoto M, Nakatani T, Inaba M: U-shaped relationship between serum uric acid levels and intrarenal hemodynamic parameters in healthy subjects. American Journal of Physiology-Renal Physiology, 2017, 312: F992-F997.

33. Kang DH, Chen W: Uric acid and chronic kidney disease: new understanding of an old problem. Seminars in Nephrology, 2011, 31: 447-452

34. Pérez-Torres I, Zuniga-Munoz AM, Guarner-Lans V: Beneficial effects of the amino acid glycine. Mini-Reviews in Medicinal Chemistry, 2017, 17: 15-32.

35. Hiratsuka C, Fukuwatari T, Sano M, Saito K, Sasaki S, Shibata $\mathrm{K}$ : Supplementing healthy women with up to $5.0 \mathrm{~g} / \mathrm{d}$ of Ltryptophan has no adverse effects. The Journal of Nutrition, 2013, 143: 859-866. 